\title{
Two one-stage posterior approaches for treating thoracic and lumbar spinal tuberculosis: A retrospective case-control study
}

\author{
ZHENGQUAN XU ${ }^{1}$, XIYANG WANG $^{1}$, XIONGJIE SHEN $^{2}$, PING WU $^{1}$, \\ XIAOYANG PANG ${ }^{1}, \mathrm{CHENGKE} \mathrm{LUO}^{1}$ and $\mathrm{HAO}^{\mathrm{ZENG}}{ }^{1}$ \\ ${ }^{1}$ Department of Spine Surgery, the Xiangya Hospital of Central South University, Changsha, Hunan 410008; \\ ${ }^{2}$ Department of Spine Surgery, the Hunan Provincial People's Hospital, Changsha, Hunan 410002, P.R. China
}

Received September 12, 2014; Accepted March 2, 2015

DOI: $10.3892 /$ etm.2015.2377

\begin{abstract}
The aim of this retrospective study was to analyze the results of two surgical treatments for thoracic and lumbar spinal tuberculosis. A total of 73 patients with monosegmental thoracic or lumbar spinal tuberculosis were enrolled from January 2006 to April 2011. The patients were divided into two groups. Patients in group A $(n=34)$ underwent one-stage posterior debridement, limited decompression, bone grafting and internal fixation combined with lamina reconstruction, while those in group B $(n=39)$ underwent one-stage posterior debridement, decompression, bone grafting and posterior instrumentation. Clinical and radiographic results were analyzed and compared between the groups. Patients were followed for a mean 31.3 months (range, 21-42 months). Fusion occurred at 4-12 months (mean, 7.7 months). Surgical complications affected one and five patients in groups A and B, respectively. There was extraction of internal fixation in two group B patients. Postoperatively, there was significant Cobb angle correction in the two groups. By the last follow-up, the Cobb angle and correction loss in group A were significantly better than that in group B; the group A Oswestry Disability Index and Frankel grade were better than that in group B. In conclusion, one-stage posterior limited decompression, bone grafting and internal fixation combined with lamina reconstruction enables rapid management of monosegmental thoracic and lumbar spinal tuberculosis with fewer complications and minimal invasion.
\end{abstract}

\section{Introduction}

As the most common form of extrapulmonary tuberculosis (TB), spinal TB has remained prevalent worldwide, particularly

Correspondence to: Mr. Xiyang Wang, Department of Spine Surgery, the Xiangya Hospital of Central South University, 139 Middle of Renmin Road, Changsha, Hunan 410008, P.R. China E-mail: wxyxydoc@163.com

Key words: posterior debridement, limited decompression, bone grafting, fixation, lamina reconstruction, spinal tuberculosis in the less developed and developing countries $(1,2)$, occurring in $1.7 \%$ of the world population (3) and accounting for almost $50 \%$ of cases of skeletal TB (4). Additionally, it can be the most dangerous form of skeletal TB due to its capacity for causing bone destruction, deformity and paraplegia (5). Anti-tuberculous chemotherapy has proven effective in the majority of cases and has become the mainstay of treatment (6), yet it cannot prevent kyphotic degeneration $(7,8)$. Surgery is therefore frequently imperative for spinal decompression (9).

Various surgical methods have been described for treating spinal TB. While there are advantages to exposing the pathological site directly and resecting damaged vertebrae, sequestra of disc and bone, and tuberculous granuloma, which cause predominantly anterior compression of the spinal cord, have led certain authors $(10,11)$ to consider the anterior approach too invasive and often unnecessary in the context of spinal TB. The anterior approach may also involve division of the diaphragm and segmental spinal vessels. An increasing number of surgeons have adopted the method of posterior debridement, bone fusion and posterior fixation to treat monosegmental spinal TB. However, complications resulting from damage to the posterior spinal column due to the posterior approach reduce the surgical effect and affect the patient's quality of life (12). A procedure that caused less damage to the posterior spinal column would be of great clinical significance. In the current study, the clinical outcomes of one-stage posterior debridement, limited decompression, bone grafting and internal fixation combined with lamina reconstruction were compared with that of single posterior debridement, decompression, interbody fusion and posterior instrumentation for treating spinal TB.

\section{Subjects and methods}

Patient information. Written informed consent was obtained from the patients and the Xiangya Hospital Ethics Committee approved the study protocol. A total of 73 patients with spinal TB (without active pulmonary TB) who had been treated at the Xiangya Hospital (Changsha, Hunan, China) from January 2006 to April 2011 were enrolled. There were 41 males and 32 females; the mean age at surgery was 38.6 years (range, 22-62 years) (Table I). The patients presented with constitutional symptoms such as back pain, limited spinal mobility, 
and a hump-shaped deformity. There was a neurological deficit in 49 patients, varying in severity from unilateral or bilateral numbness and lower extremity weakness to walking disorders (Table II). The pre-operative erythrocyte sedimentation rate (ESR) and Oswestry Disability Index (ODI) were abnormal (Table III).

Diagnosis was based on non-specific laboratory and imaging findings, including spinal radiographic films, computed tomography (CT) and magnetic resonance imaging. The mean disease course was 10 months (range, 3-16 months). The findings showed the following indications for surgery: i) Progressive neurological deficit; ii) persistent pain due to instability; iii) severe kyphosis or kyphosis likely to progress (9); iv) poor outcome following conservative treatment. Patients who met the surgical criteria were assigned to group A or B. Patients in the former group underwent one-stage posterior debridement, limited decompression, bone grafting and internal fixation combined with lamina reconstruction. Patients in the latter group underwent single posterior debridement, decompression, bone grafting and instrumentation. In practice, it is challenging to randomly select a surgical treatment method clinically; therefore, in the present study, cases in group B were collected earlier while cases in group A were collected in more recent years. The same team reviewed the surgical indications and performed the procedures. Table I lists the characteristics of each group.

Pre-operative procedure. The patients received standard anti-tuberculous chemotherapy $(300 \mathrm{mg} /$ day isoniazid, $450 \mathrm{mg}$ /day rifampicin, $750 \mathrm{mg} /$ day ethambutol and $750 \mathrm{mg} /$ day pyrazinamide) for an average 2-3 weeks prior to surgery. The surgery was postponed until anemia and hypoproteinemia recovered and there was a general significant decrease in ESR.

Surgical method. Group A patients were placed in the prone position and surgery was performed under general endotracheal anesthesia. Pedicle screws were placed according to the level of decompression required based on pre-operative imaging. A temporary, pre-bent rod was then stabilized on the mildly affected side of the focus to avoid spinal cord injury during decompression and focal debridement. The side on which the infection was predominant was selected. Unilateral facetectomy and laminectomy up to the medial pedicle edge were performed. If required $1.0-1.5 \mathrm{~cm}$ were removed from the rib adjacent to the thoracic spine (Fig. 1). To decompress the spinal cord, lesions were removed through to healthy bleeding bone using curettes of various sizes and angles. Somatosensory-evoked potential monitoring was performed to avoid spinal cord injury. Thoracic nerve roots on the focal side were sacrificed for better exposure. The operating table was then tilted $30^{\circ}$ to the opposite side for a better view to enable complete removal of the lesions. Pus and necrotic tissue were eliminated by pressurized washing using a soft catheter inserted into the deep part of the lesion during surgery and negative pressure suction. The appropriate shaping allograft or autograft was embedded in the bone interbody. Subsequently, an allograft or autograft plate was embedded in the lamina defect area excised for focal debridement. To complete the lamina reconstruction, the rod on the decompressed side and
Table I. Patient characteristics.

\begin{tabular}{lccc}
\hline Characteristics & Group A & Group B & P-value \\
\hline Gender & & & 0.964 \\
Male & 19 & 22 & \\
Female & 15 & 17 & \\
Mean age (years) & $38.7 \pm 8.0$ & $38.4 \pm 8.3$ & 0.888 \\
$\begin{array}{l}\text { Pathological region } \\
\text { Thoracic }\end{array}$ & 15 & 17 & 0.964 \\
$\quad$ Thoracolumbar & 10 & 12 & 0.900 \\
$\quad$ Lumbar & 9 & 10 & 0.319 \\
Concurrent disease & & & \\
$\quad$ Hypertension & 4 & 5 & 0.891 \\
$\quad \begin{array}{l}\text { Diabetes } \\
\text { Coronary heart disease }\end{array}$ & 5 & 7 & 0.709 \\
$\quad \begin{array}{l}\text { Electrocardiographic } \\
\text { abnormality }\end{array}$ & 8 & 9 & 0.567 \\
& & 11 & 0.650 \\
\end{tabular}

cross-linkage were connected to immobilize the bone plate. Streptomycin $(1.0 \mathrm{~g})$ and isoniazid $(0.2 \mathrm{~g})$ were administered locally, and drainage and incision suturing were performed postoperatively. The debrided material was sent for culture and histopathological examination.

Group B patients underwent expanded hemilaminectomy (resection of the spinous process, unilateral facet joint, pedicles and transverse process). The exposed dural sac and posterior body bone defects were not covered with a bone plate. Other procedures were the same as that for group A.

Postoperative procedure. Typically, the drain was removed when drainage flow was $<50 \mathrm{ml} / 24 \mathrm{~h}$. With assistance from a plastic orthosis, the patients were allowed to start walking gradually after remaining supine for an average of four weeks postoperatively, depending on their recovery of lower limb muscle power. The brace was discarded $\leq 12$ months postoperatively. The patients were treated with the above-mentioned anti-TB chemotherapy regimen for 12-18 months postoperatively and the ESR and hepatic function were examined regularly.

Evaluation standard and statistical analysis. Immediately following surgery, routine lateral and anteroposterior radiographs and a CT (Brilliance 16-slice; Philips, Andover, MA, USA) were obtained to assess the placement of graft and instrumentation and formation of sequestra. The overall mean follow-up period was 31.3 months (range, 21-42 months). The following indices were recorded pre- and postoperatively and during follow-up: i) Cobb angle; ii) angle loss rate, which was calculated as follows: [(Cobb angle at the last visit)-(postoperative Cobb angle)/(preoperative Cobb angle)] x100\%; iii) neurological status according to the Frankel classification; iv) ESR; v) ODI; and vi) fusion status evaluated according to Lee et al (13).

Statistical analyses were performed using SPSS software (version 17.0; SPSS Inc., Chicago, IL, USA). Changes in laboratory and physical parameters in the two groups were 
Table II. Neurological recovery according to the American Spinal Injury Association grade (groups A and B).

\begin{tabular}{|c|c|c|c|c|c|c|c|c|c|c|c|}
\hline \multirow[b]{2}{*}{ Pre-operation } & \multirow{2}{*}{$\begin{array}{c}\text { Group A/B } \\
n / n\end{array}$} & \multicolumn{5}{|c|}{ Group A final follow-up } & \multicolumn{5}{|c|}{ Group B final follow-up } \\
\hline & & A & B & $\mathrm{C}$ & $\mathrm{D}$ & E & A & B & $\mathrm{C}$ & $\mathrm{D}$ & $\mathrm{E}$ \\
\hline A & $0 / 0$ & & & & & & & & & & \\
\hline B & $2 / 2$ & & & 1 & 1 & & & & 2 & & \\
\hline $\mathrm{C}$ & $9 / 11$ & & & 1 & 3 & 5 & & & 1 & 5 & 5 \\
\hline D & $12 / 13$ & & & & & 12 & & & & & 13 \\
\hline $\mathrm{E}$ & $11 / 13$ & & & & & 11 & & & & & 13 \\
\hline
\end{tabular}

Table III. Patient clinical data.

\begin{tabular}{|c|c|c|c|c|c|c|c|c|}
\hline \multirow{2}{*}{ Group } & \multirow{2}{*}{$\begin{array}{c}\text { Surgery } \\
\text { duration }(\min )\end{array}$} & \multirow{2}{*}{$\begin{array}{l}\text { Amount of } \\
\text { bleeding (ml) }\end{array}$} & \multirow{2}{*}{$\begin{array}{c}\text { Hospital } \\
\text { stay (days) }\end{array}$} & \multicolumn{2}{|c|}{ ESR } & \multicolumn{2}{|c|}{ ODI } & \multirow{2}{*}{$\begin{array}{l}\text { Fusion time } \\
\text { (months) }^{\mathrm{e}}\end{array}$} \\
\hline & & & & Pre & $\operatorname{Post}^{\mathrm{c}}$ & Pre & $\mathrm{LV}^{\mathrm{d}}$ & \\
\hline A & $171.4 \pm 12.2$ & $717.6 \pm 110.8$ & $13.5 \pm 2.1$ & $\begin{array}{l}53.9 \pm \\
15.9\end{array}$ & $\begin{array}{c}10.4 \pm \\
2.6\end{array}$ & $\begin{array}{c}40.2 \pm \\
3.9\end{array}$ & $\begin{array}{c}10.1 \pm \\
3.0\end{array}$ & $7.2 \pm 1.5$ \\
\hline B & $160.4 \pm 15.6^{\mathrm{a}}$ & $803.1 \pm 124.6^{\mathrm{a}}$ & $14.0 \pm 2.9^{b}$ & $\begin{array}{l}55.0 \pm \\
15.6\end{array}$ & $\begin{array}{l}9.1 \pm \\
2.4\end{array}$ & $\begin{array}{c}39.7 \pm \\
4.0\end{array}$ & $\begin{array}{c}20.6 \pm \\
3.0\end{array}$ & $8.1 \pm 1.5$ \\
\hline
\end{tabular}

${ }^{\text {aS }}$ tudent-Newman-Keuls test, comparison with group A, $\mathrm{P}<0.05$, ${ }^{\mathrm{b} S t u d e n t-N e w m a n-K e u l s ~ t e s t, ~ c o m p a r i s o n ~ w i t h ~ g r o u p ~ A, ~} \mathrm{P}=0.409$, ${ }^{\mathrm{c}}$ Student-Newman-Keuls test comparing post ESR between the two groups, $\mathrm{P}=0.019$, ${ }^{\mathrm{d}}$ Student-Newman-Keuls test comparing LV ODI between the two groups, $\mathrm{P}<0.05$, ${ }^{\mathrm{e}}$ Student-Newman-Keuls test comparing fusion time between the two groups, $\mathrm{P}=0.017$. Data are presented as mean \pm standard deviation. Pre, pre-operative; Post, post-operative; LV, last visit; ESR, erythrocyte sedimentation rate; ODI, Oswestry Disability Index.

A

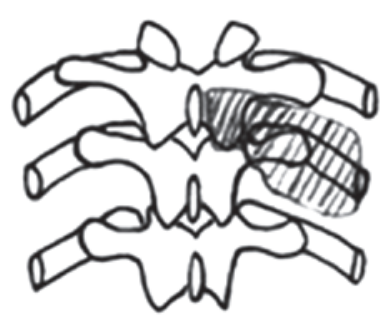

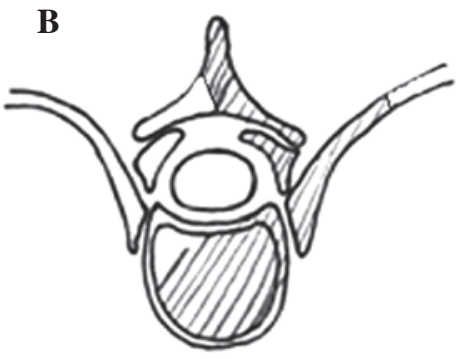

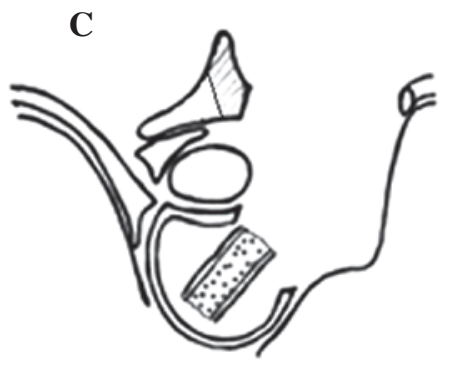

Figure 1. Resection range (shaded portion). The (A) facet joint, (B) costotransverse joint and (C) small portion of ribs, and bone graft were resected in lesions following the debridement.

compared using the Student-Newman-Keuls test. Any discrepancy in normal distribution was analyzed using the rank sum test. $\mathrm{P}<0.05$ indicated statistical significance.

\section{Results}

The overall mean follow-up was 31.3 months (range, 21-42 months). Table I shows the patient data and the neurological status is listed in Table II. No severe neurological complications were observed in either group. The surgery time, amount of bleeding and length of hospital stay was recorded for each patient following surgery (Table III). The ESR returned to normal within three months postoperatively (Table III). By the last visit, the group A ODI values were significantly lower than those of group $\mathrm{B}(\mathrm{P}<0.05)$ (Table III). Compared with the pre-operative values, the ODI values for the two groups were greatly improved $(\mathrm{P}<0.05)$.

In group $\mathrm{A}$, all the grafted bones ultimately fused with the fusion time ranging 4-10 months (mean, 7.2 months) (Fig. 2). The grafts in all but two subjects in group B ultimately fused, with the fusion time ranging 6-12 months (mean, 8.1 months) (Fig. 3). Fusion in two patients was delayed due to extraction of internal fixation. CT scans detected no sequestra in any of the cases during follow-up.

Table IV lists the Cobb angles recorded during follow-up. There were significant differences between the pre- and 


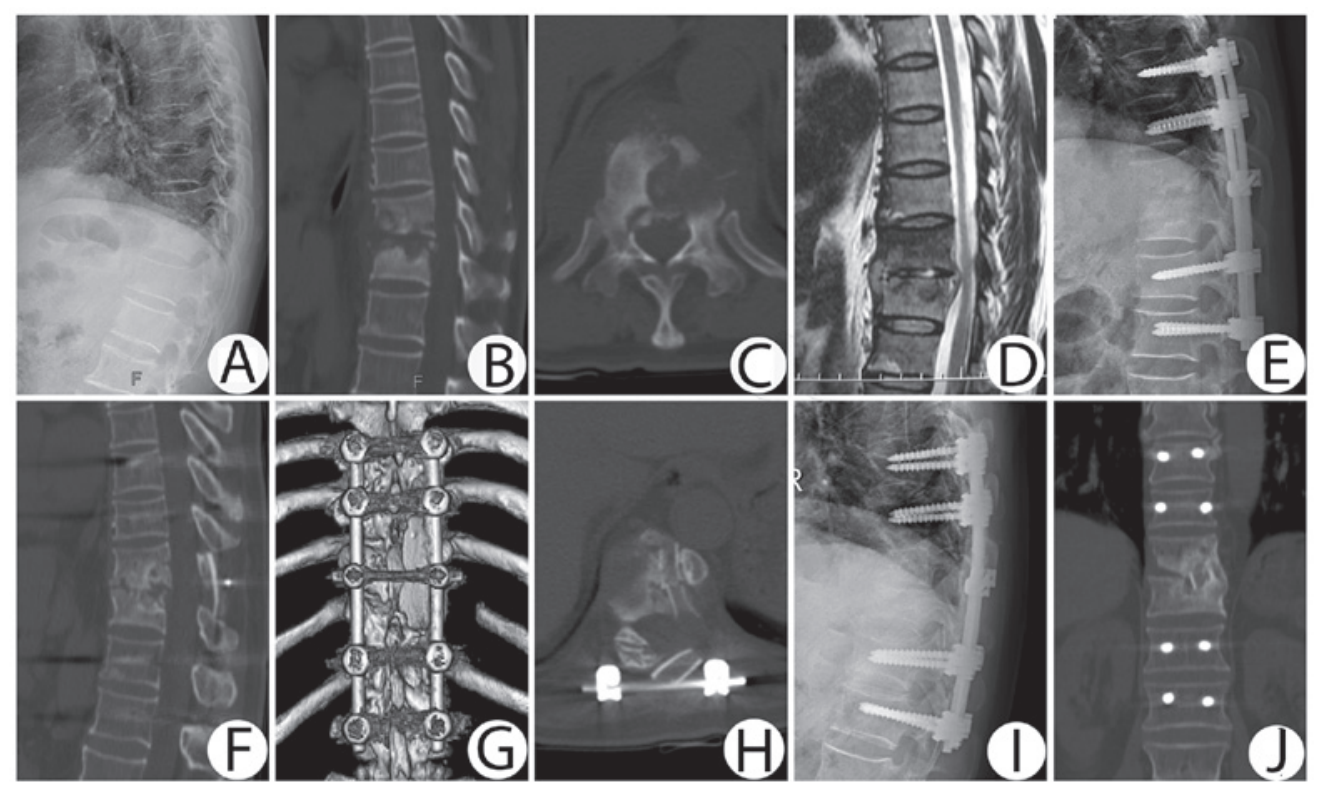

Figure 2. A 58-year-old male with T10 and T11 lesions involving bone destruction, epidural cold abscess formation and kyphosis angle of $24^{\circ}$ underwent one-stage posterior debridement, limited decompression, bone grafting and internal fixation combined with lamina reconstruction. (A-D) Pre-operative images. (E) Postoperative radiograph revealing that kyphosis was corrected to $8^{\circ}$. (F-H) CT revealing a clear gap between the reconstructed lamina and dural sac with no evident scar tissue formation; the reconstructed lamina was in situ. (I and J) Postoperative radiograph and CT at 30 months depicting internal fixation in a good position, $2^{\circ}$ loss of kyphosis angle and bone fusion.CT, computed tomography.
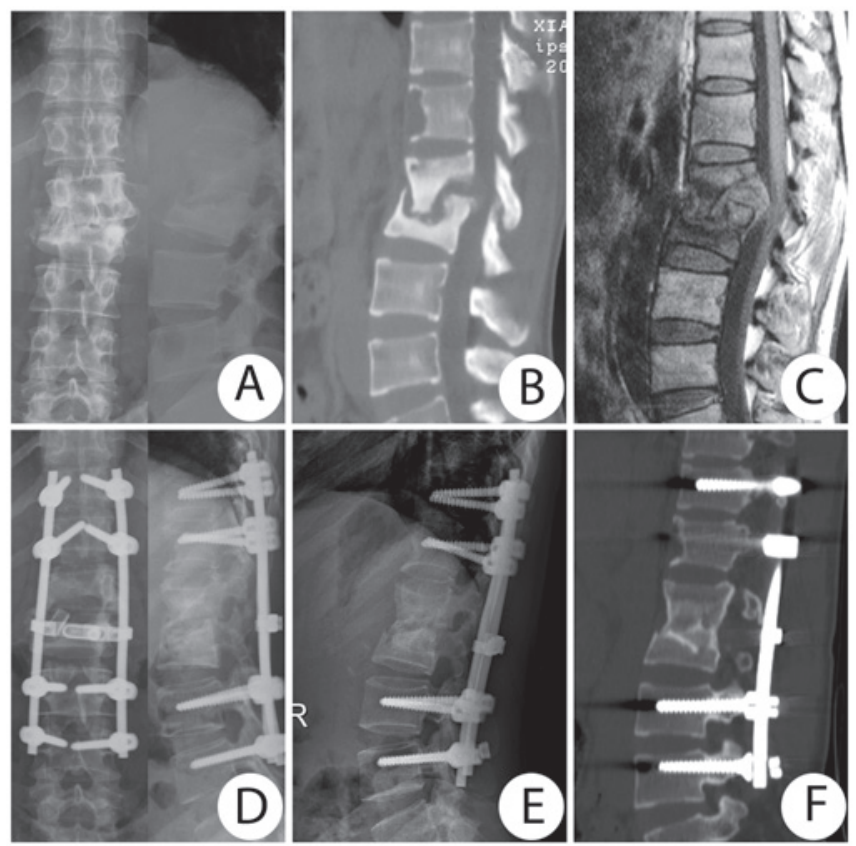

Figure 3. A 34-year-old female with L1 and L2 lesions involving bone destruction, epidural cold abscess formation and a kyphosis angle of $32^{\circ}$ underwent one-stage posterior debridement, decompression, interbody fusion and posterior instrumentation. (A-C) Pre-operative images. (D) Postoperative radiograph indicating that kyphosis was corrected to $2^{\circ}$. (E) Postoperative computed tomography at nine months depicting successful fusion. (F) Image at 24-month follow-up indicating the fixation in good shape, a kyphosis angle of $6^{\circ}$ and no signs of tuberculosis recurrence.

postoperative values $\left(\mathrm{P}_{\mathrm{A}}<0.05, \mathrm{P}_{\mathrm{B}}<0.05\right)$ for the two groups. No significant difference was observed immediately postoperatively between the two groups $(\mathrm{P}=0.396)$. However, at the last follow-up, there was a significant difference between loss of correction, angle loss rate and Cobb angle between the two groups $(\mathrm{P}<0.05)$.

There was superficial infection in one incision in group A, which was treated successfully with antibiotics. Five group B patients experienced surgical complications. There was superficial infection in one incision, which was managed successfully with antibiotics. One patient, who suffered from sinus drainage tube formation one week postoperatively, was successfully treated by weekly local isoniazid therapy. Extraction of internal fixation was detected in two patients at the eight- and 10-month follow-up, respectively, which were successfully treated with anterior debridement and interbody fusion combined with long-segment posterior instrumentation. One patient had refractory intercostal neuralgia, which was relieved by non-steroidal anti-inflammatory drugs.

\section{Discussion}

Despite ongoing efforts by the World Health Organization and local health authorities, TB remains prevalent in certain developing countries, affecting all susceptible individuals (14). Over the last 50 years, various methods for surgical debridement and fusion have been described for spinal TB $(1,10,15)$. The purpose of any procedure is obtaining adequate decompression and visualization for intervention, and achieving spinal stability. With the improvement of internal fixation devices, many surgeons (16-18) have reported that a posterior approach to fixation achieves good results in the treatment of spinal TB. Firstly, posterior spinal fusion avoids the possible hazards of breaching the thoracic or abdominal cavities. Additionally, the pedicle screw, the strongest part of the vertebral body, provides three-dimensional correction and stabilization, which is much stronger than anterior instrumentation. This approach, 
Table IV. Patient clinical data.

\begin{tabular}{|c|c|c|c|c|c|}
\hline \multirow{2}{*}{$\begin{array}{l}\text { Pathological } \\
\text { region }\end{array}$} & \multicolumn{4}{|c|}{ Cobb angle $\left({ }^{\circ}\right)$} & \multirow{2}{*}{$\begin{array}{c}\text { Angle loss } \\
\text { rate }^{\mathrm{e}}\end{array}$} \\
\hline & $\operatorname{Pre}^{a}$ & $\operatorname{Post}^{b^{*}}$ & $\mathrm{LV}^{\mathrm{c}}$ & $\mathrm{LC}^{\mathrm{d}}$ & \\
\hline \multicolumn{6}{|l|}{ Group A } \\
\hline Thoracic & $28.8 \pm 6.1$ & $6.4 \pm 1.6$ & $8.7 \pm 1.8$ & $2.2 \pm 1.0$ & $8.3 \pm 4.4$ \\
\hline Thoracolumbar & $32.9 \pm 6.5$ & $8.5 \pm 2.7$ & $10.8 \pm 2.8$ & $2.3 \pm 1.0$ & $7.5 \pm 4.9$ \\
\hline Lumbar & $27.5 \pm 7.2$ & $5.4 \pm 2.9$ & $6.9 \pm 2.9$ & $1.5 \pm 0.8$ & $6.0 \pm 4.4$ \\
\hline \multicolumn{6}{|l|}{ Group B } \\
\hline Thoracic & $29.2 \pm 5.5$ & $7.2 \pm 1.9$ & $12.1 \pm 1.9$ & $4.9 \pm 1.0$ & $17.3 \pm 6.0$ \\
\hline Thoracolumbar & $30.5 \pm 5.6$ & $7.7 \pm 2.6$ & $12.5 \pm 2.5$ & $4.8 \pm 0.9$ & $16.5 \pm 5.3$ \\
\hline Lumbar & $26.1 \pm 4.7$ & $6.8 \pm 2.4$ & $11.8 \pm 2.5$ & $5.0 \pm 1.3$ & $19.9 \pm 6.8$ \\
\hline \multicolumn{6}{|c|}{ 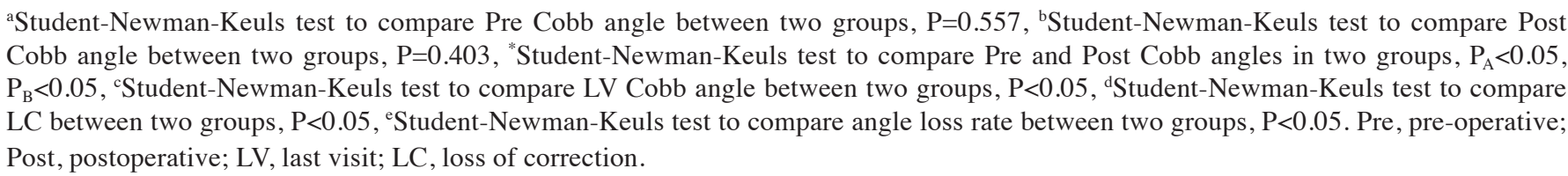 } \\
\hline
\end{tabular}

however, destroys the posterior spinal column, resulting in spinal instability (19).

In 1983, Denis (20) first described the three-column model concept of the spine to elucidate the instability of spinal trauma. Biomechanical and pathomechanical studies have demonstrated that intact middle and posterior column structures play a key role in spinal stability (21). Xie et al (22) noted that the posterior spinal column was critical for maintaining spinal stability and resistance to shear force and rotational force. Similarly, Degreif et al (23) reported that laminectomy caused $27 \%$ rotational stability loss. Therefore, a surgical approach that causes minimal structural damage to the posterior spinal column is of great clinical significance for preventing postoperative complications in the treatment of spinal TB.

Raimondi et al (24) first described lamina replacement following an intraspinal approach in 1976. More recently, several studies reported the usefulness of lamina reconstruction for treating spinal or spinal cord injury, achieving good clinical and biomechanical outcomes $(25,26)$. In the present study, the method of lamina reconstruction based on one-stage posterior debridement, limited decompression, bone grafting and internal fixation was used to treat monosegmental spinal TB in group A and good clinical efficacy was achieved. There were significant differences between the loss of correction and angle loss rate of groups A and B. Angle correction in group A was retained more satisfactorily than that in group B, with only $2.0^{\circ}$ Cobb angle loss, which is better than the result of Louw et al $\left(3.3^{\circ}\right)$ (27). Additionally, the fusion time of bone grafts in group A was shorter than that in group B, reducing the risk of failure of internal fixation. There was extraction of internal fixation in two group B patients but not in group A patients.

Chandler et al (28) indicated that considerable scar tissue filled the gap following laminectomy, forming a scar tissue membrane layer, and abnormal proliferation of fibrous connective tissue often adhered to the dural sac and nerve root, causing a sequence of nerve compression symptoms. The formation of scar tissue would eventually lead to failed back surgery syndrome, affecting the patient's life adversely $(29,30)$. An effective and safe mechanical barrier, lamina reconstruction forms a relatively enclosed environment, preventing invasion and suppression by posterior organization. It effectively overcame the drawback of dural sac compression resulting from hematoma and organization formation following the implantation of other materials. Compared with the results in group B, a better quality of life of the patients in group A, reflected by the ODI, was achieved following surgery. The ODI decrease in group A was more significant than that in group B.

The difficulty underlying the use of this approach to treat spinal TB stems from whether such an approach can achieve complete focal debridement, and how the reconstructed lamina can be prevented from subsiding into the spinal canal. The approach offers no advantage in terms of debridement; however, with the development of effective anti-TB drugs, tuberculous lesions may be successfully treated through spontaneous fusion, and complete debridement is not unduly emphasized (31,32). To prevent subsidence of the reconstructed lamina, it was attached to the vertebral plate adjacent to the lesion during the surgery.

The six factors constituting the main advantages this approach has over other methods include that: i) It minimizes damage to spinal stability, overcoming the shortcomings of a large fixation range and retaining more motor units of the spine. ii) Satisfactory Cobb angle correction can be achieved, with less angle loss and assurance of spinal stability. iii) It effectively prevents postoperative instability, subluxation and kyphotic deformities. iv) The technique allows conservation of the bone protecting the spinal cord and prevents epidural adhesion following laminectomy. v) Lamina replantation enables muscle and soft tissue attachment, increasing postoperative paraspinal muscle function. vi) The procedure can also relieve spinal nerve compression, reduce trauma for patients, and improve their quality of life more effectively.

There are limits to this procedure, however. Based on experience, the indications for the method are as follows: i) Cases 
with monosegmental TB or single vertebral TB; ii) paraspinal abscess confined to one segment; and iii) Cobb angle of the lesion $<45^{\circ}$. Conversely, the procedure cannot be performed in the following situations: i) multi-segmental vertebral TB; ii) multi-level non-contiguous spinal $\mathrm{TB}$; iii) paraspinal abscess diffused across two segments or accompanied by psoas abscess or iliac fossa abscess; and iv) case combined with complete paraplegia.

Due to controversy regarding the treatment of spinal TB, each case should be considered individually. When formulating a successful surgical plan, practitioners should consider the severity of the disease, individual patient differences and available surgical expertise and facilities.

In conclusion, surgical treatment involving one-stage posterior limited decompression, bone grafting and internal fixation combined with lamina reconstruction can be an effective treatment method for monosegmental thoracic and lumbar TB. This method can lead to the effective recovery of posterior spinal column integrity, improve neurological function and reduce postoperative complications. Thus far, the clinical and radiographic results of the patients are good. However, these are preliminary results from a small study population and certain patients had a relatively short follow-up. Future investigations with a larger number of patients and a longer follow-up is required.

\section{Acknowledgements}

This study was partially funded by the National Natural Science Foundation of China (no. 81171736).

\section{References}

1. Chen WJ, Chen $\mathrm{CH}$ and Shih $\mathrm{CH}$ : Surgical treatment of tuberculous spondylitis. 50 patients followed for 2-8 years. Acta Orthop Scand 66: 137-142, 1995.

2. Garst RJ: Tuberculosis of the spine: a review of 236 operated cases in an underdeveloped region from 1954 to 1964 . J Spinal Disord 5: 286-300, 1992 .

3. Gautam MP, Karki P, Rijal S and Singh R: Pott's spine and paraplegia. JNMA J Nepal Med Assoc 44: 106-115, 2005.

4. Fuentes Ferrer M, Gutiérrez Torres L, Ayala Ramírez O, Rumayor Zarzuelo M, del Prado González N: Tuberculosis of the spine. A systematic review of case series. Int Orthop 36: 221-231, 2012.

5. Cavuşoğlu H, Kaya RA, Türkmenoğlu ON, Tuncer C, Colak I and Aydin Y: A long-term follow-up study of anterior tibial allografting and instrumentation in the management of thoracolumbar tuberculous spondylitis. J Neurosurg Spine 8: 30-38, 2008.

6. Moon MS, Moon YW, Moon JL, Kim SS and Sun DH: Conservative treatment of tuberculosis of the lumbar and lumbosacral spine. Clin Orthop Relat Res 398: 40-49, 2002.

7. Rajasekaran S and Shanmugasundaram TK: Prediction of the angle of gibbus deformity in tuberculosis of the spine. J Bone Joint Surg Am 69: 503-509, 1987.

8. Rajasekaran S: The natural history of post-tubercular kyphosis in children. Radiological signs which predict late increase in deformity. J Bone Joint Surg Br 83: 954-962, 2001.

9. Jain AK: Tuberculosis of the spine: a fresh look at an old disease. J Bone Joint Surg Br 92: 905-913, 2010.

10. McDonnell MF, Glassman SD, Dimar JR II, Puno RM and Johnson JR: Perioperative complications of anterior procedures on the spine. J Bone Joint Surg Am 78: 839-847, 1996.
11. Ikard RW: Methods and complications of anterior exposure of the thoracic and lumbar spine. Arch Surg 141: 1025-1034, 2006.

12. Garg B, Kandwal P, Nagaraja UB, Goswami A and Jayaswal A: Anterior versus posterior procedure for surgical treatment of thoracolumbar tuberculosis: A retrospective analysis. Indian J Orthop 46: 165-170, 2012.

13. Lee CK, Vessa P and Lee JK: Chronic disabling low back pain syndrome caused by internal disc derangements. The results of disc excision and posterior lumbar interbody fusion. Spine 20: 356-361, 1995.

14. Zhang HQ, Li JS, Zhao SS, Shao YX, Liu SH, Gao Q, Lin MZ, Liu JY, Wu JH and Chen J: Surgical management for thoracic spinal tuberculosis in the elderly: posterior only versus combined posterior and anterior approaches. Arch Orthop Trauma Surg 132: 1717-1723, 2012.

15. Moon MS: Tuberculosis of the spine. Controversies and a new challenge. Spine 22: 1791-1797, 1997.

16. Moon MS, Woo YK, Lee KS, Ha KY, Kim SS and Sun DH: Posterior instrumentation and anterior interbody fusion for tuberculous kyphosis of dorsal and lumbar spines. Spine 20: 1910-1916, 1995

17. Lee SH, Sung JK and Park YM: Single-stage transpedicular decompression and posterior instrumentation in treatment of thoracic and thoracolumbar spinal tuberculosis: a retrospective case series. J Spinal Disord Tech 19: 595-602, 2006.

18. Talu U, Gogus A, Ozturk C, Hamzaoglu A and Domanic U: The role of posterior instrumentation and fusion after anterior radical debridement and fusion in the surgical treatment of spinal tuberculosis: experience of 127 cases. J Spinal Disord Tech 19: 554-559, 2006.

19. Jarrett CD, Heller JG and Tsai L: Anterior exposure of the lumbar spine with and without an 'access surgeon': morbidity analysis of 265 consecutive cases. J Spinal Disord Tech 22: 559-564, 2009.

20. Denis F: The three column spine and its significance in the classification of acute thoracolumbar spinal injuries. Spine 8: 817-831, 1983.

21. Ogden AT, Bresnahan L, Smith JS, Natarajan R and Fessler RG: Biomechanical comparison of traditional and minimally invasive intradural tumor exposures using finite element analysis. Clin Biomech (Bristol, Avon) 24: 143-147, 2009.

22. Xie J, Li T, Wang Y, Zhao Z, Zhang Y and Bi N: Change in Cobb angle of each segment of the major curve after posterior vertebral column resection (PVCR): a preliminary discussion of correction mechanisms of PVCR. Eur Spine J 21: 705-710, 2012.

23. Degreif J, Wenda K, Runkel M and Ritter G: Rotational stability of the thoracolumbar spine after interlaminar ultrasound window, hemilaminectomy and laminectomy. A comparative experimental study. Unfallchirurg 97: 250-255, 1994 (In German).

24. Raimondi AJ, Gutierrez FA and Di Rocco C: Laminotomy and total reconstruction of the posterior spinal arch for spinal canal surgery in childhood. J Neurosurg 45: 555-560, 1976.

25. Matsui H, Kanamori M and Miaki K: Expansive laminoplasty for lumbar intradural lipoma. Int Orthop 21: 185-187, 1997.

26. Shikata J, Yamamuro T, Shimizu K and Saito T: Combined laminoplasty and posterolateral fusion for spinal canal surgery in children and adolescents. Clin Orthop Relat Res 259: 92-99, 1990.

27. Louw JA: Spinal tuberculosis with neurological deficit. Treatment with anterior vascularised rib grafts, posterior osteotomies and fusion. J Bone Joint Surg Br 72: 686-693, 1990.

28. Chandler K and Cappello R: Laminectomy membrane formation in dogs: is the answer still elusive? Vet J 172: 1-2, 2006.

29. Ross JS, Robertson JT, Frederickson RC,Petrie JL, ObuchowskiN, Modic MT and deTribolet N: Association between peridural scar and recurrent radicular pain after lumbar discectomy: magnetic resonance evaluation. ADCON-L European Study Group. Neurosurgery 38: 855-861, discussion 861-863, 1996.

30. Fritsch EW, Heisel J and Rupp S: The failed back surgery syndrome: reasons, intraoperative findings, and long-term results: a report of 182 operative treatments. Spine 21: 626-633, 1996.

31. Pande KC and Babhulkar SS: Atypical spinal tuberculosis. Clin Orthop Relat Res 398: 67-74, 2002.

32. Rajasekaran S: The problem of deformity in spinal tuberculosis. Clin Orthop Relat Res 398: 85-92, 2002. 